\title{
New Scenarios for a Shift towards Agroecology in Viticulture
}

\author{
Nawel Aouadi ${ }^{1}$, Francis Macary ${ }^{1 *}$ (1) , Laurent Delière ${ }^{2,3}$, Jean-Philippe Roby ${ }^{4}$ \\ ${ }^{1}$ INRAE, ETBX, F-33612 Cestas, France \\ ${ }^{2}$ INRAE, SAVE, Bordeaux Sciences Agro, Univ. Bordeaux, F-33140 Villenave d'Ornon, France \\ ${ }^{3}$ INRAE, UE Vigne Bordeaux, F-33140 Villenave d'Ornon, France \\ ${ }^{4}$ INRAE, EGFV, Bordeaux Sciences Agro, Univ. Bordeaux, F-33140 Villenave d'Ornon, France \\ Email: *francis.macary@inrae.fr
}

How to cite this paper: Aouadi, N., Macary, F., Delière, L. and Roby, J.-P. (2021) New Scenarios for a Shift towards Agroecology in Viticulture. Agricultural Sciences, 12, 1003-1033.

https://doi.org/10.4236/as.2021.1210065

Received: July 16, 2021

Accepted: September 27, 2021

Published: September 30, 2021

Copyright (c) 2021 by author(s) and Scientific Research Publishing Inc. This work is licensed under the Creative Commons Attribution International License (CC BY 4.0).

http://creativecommons.org/licenses/by/4.0/

\begin{abstract}
In the light of its negative impacts on the environment and human health, conventional agriculture is currently facing new challenges; for example, reducing pesticide reliance, improving biodiversity, adapting to climate change and reconciling winegrowers with consumers, which require changes to be made to vineyard management. A shift towards more sustainable agriculture via the development of agroecological systems may be key to meeting these environmental, economic and social challenges. This study aimed to evaluate the performance of existing viticultural systems, as well as that of three new scenarios that we built to change conventional vine production systems and their related practices. The end aim is to adopt the principles of agroecology, and more virtuously, to ensure that vine production remains in line with societal expectations. First, thirty-eight different viticultural systems were chosen. Three realistic scenarios for changing these production systems were then built by working with stakeholders and incorporating the best practices that had been identified in the vineyard. Conventional practices were optimised in the first scenario and an agroecological approach was adopted for the other two scenarios: an Agroecological scenario (using synthetic chemicals) and an Agroecological-Bio scenario (organic system). All three scenarios were based on a combination of good practices which contribute to enhancing vineyard biodiversity, and which thus restore biological regulation and in turn reduce pesticides. The viticultural systems performances have been evaluated with a methodology involving multicriteria decision aid using ELECTRE Tri-C and ELECTRE III methods. Seven evaluation criteria were selected which covered socio-economic performance (economic profitability, workload and system complexity) and environmental performance (pesticide pressure, pesticide ecotoxicity, agroecological practices and pesticide drift).
\end{abstract}


The best performances were achieved by the two agroecological scenarios, and this methodology can be adaptable to different production systems everywhere in different viticultural regions.

\section{Keywords}

Viticultural System, Agroecology, Biodiversity, Pesticides, Multicriteria

Decision Aid Methods, ELECTRE Methods

\section{Introduction}

The negative impacts of intensive agriculture and necessity for a shift towards more sustainable farming systems

One and a half centuries of agriculture has seen intensification in agricultural practices and an increase in chemical treatments: fertilisers to improve yields, pesticides to control cryptogams and pests, and weed control to manage competition from harmful weeds [1]. This situation applies to orchards and viticulture in particular [2], where the aim is to obtain satisfactory yields and high quality grapes necessary for the production of good wines. However, the excessive use of pesticides has also led to water and soil contamination, biodiversity reduction and human health problems [3] [4] [5].

Many studies have shown that there was a relationship between long-term exposure to pesticides and the development of acute and chronic diseases [6] [7]. There is also evidence that different components of the environment are contaminated with pesticide residues, especially surface and groundwater [3]. The role of pesticide use in biodiversity loss has also been proven, particularly in relation to bees and different auxiliary insects, which are the natural enemies of crop pests [8] [9]. The short term effects of pesticides are linked to the direct exposure of non-target organisms, and the long-term effects involve changes to landscapes, habitats and the food chain [10].

There is therefore an urgent need to reduce pesticide use and to develop more sustainable production systems that integrate the concepts of agroecology.

Agroecology is considered to be either a scientific discipline offering a systemic analysis by integrating human and social sciences, a set of practices integrating the principles of ecology in agronomy (working with nature), or a social movement [11] [12] [13]. Altieri [14] evoked the notion of the agroecology of productive systems, in which the principles of ecology are applied to agriculture. Baret [15] considers agroecology as a set of principles for action based on two main ideas: 1) we should work alongside nature and not against it; it is therefore an agricultural system that relies on the natural functioning of an ecosystem, 2) agriculture must be economically efficient, the goal being to earn a living and feed a family; it thus needs to be regarded as a system rather than a plot of land.

In viticulture more specifically, Gary et al. [16] highlighted the importance of 
the development of agroecological vineyards which combine management innovations and land use planning at plot, farm and landscape level. Garcia et al. [17] studied the impact of soil management strategies and the extent to which the root characteristics of plant communities and soil organic carbon explain the stability of soil aggregates in vineyards. Nicholls et al. [18] provided a practical agroecological methodology for rapidly assessing soil quality and crop health in viticultural systems using simple indicators, which were jointly chosen, applied and interpreted by farmers and researchers.

Designing and evaluating new farming systems to improve the relationship between agriculture and ecosystems: a focus on viticulture

There are several approaches to designing innovative cropping systems. The so-called "prototyping" approach is a combination of the following: a regional diagnosis to identify a set of constraints and objectives, expert knowledge to build new cropping systems and on-site experimentation on the prototypes to assess and adjust these systems [19] [20]. This approach was used by the EcoViti network to re-design intensive perennial systems in order to reduce pesticide use while maintaining yield and economic performance [21]. The theoretical prototypes were designed by experts and stakeholders for each set of objectives and constraints, and experimented on in many regions. The results indicated that the prototyping method had potential for achieving fixed objectives.

The "iterative design" is an experiment-based approach that aims to progressively improve existing systems in order to achieve the predefined objectives [22]. Innovative cropping systems can also be designed using a range of simulation-based approaches [23]. These approaches are commonly used to generate diverse crop rotations in arable systems.

The design of innovative cropping systems is often associated with an assessment of their performance or sustainability, for which a set of criteria is required. The choice of criteria and associated indicators depends on the aim of the evaluation, whether it be to evaluate the overall sustainability of the farming system [24] [25] or to evaluate one or several particular components of sustainability [26].

The criteria also depend on what is being assessed (i.e., real prototypes (ex post assessment) vs virtual prototypes (ex ante)), as well as on the scale of the evaluation or organisational level (e.g., the cropping system, type of farm and regional status). Furthermore, both the availability of data and the data acquisition process influence the choice of criteria for the evaluation [26].

There are different approaches to analysing selected criteria. Non-aggregative methods involve the analysis of elementary criteria using descriptive statistics (e.g., correlation tests, data distribution and graphical plots), multidimensional statistics (e.g., clustering analysis) or using linear model-based methods (e.g., linear regression; [26]). Performance profiles using multivariate analysis and cluster analysis are considered to belong to an intermediate level of aggregation. The criteria for evaluation can be aggregated into a composite criterion (e.g., normalised indicators) via 
the use of models (i.e., DEXiPM, MASC and ELECTRE methods).

\section{The use of ELECTRE methods in environmental science}

Several studies have applied outranking methods to assess the sustainability of cropping systems; for example, Arondel and Girardin [27] used the ELECTRE TRI method to assess the impact of cropping systems on groundwater quality. ELECTRE methods have also been used to evaluate winter wheat management plans for reconciling conflicting economic, environmental and technological requirements [28].

In environmental science, ELECTRE methods have been adopted in many studies to assess the risk of pesticides applied in agriculture ending up in water sources by combining ELECTRE III and Tri-C models with GIS [29] [30].

The aim of this study was first to assess existing viticultural systems within the study vineyard, then to design scenarios for new systems which would show how the adoption of agroecological practices contributes to the improvement of production systems in terms of biodiversity, reduction of pesticides, soil quality and profitability. The study was carried out in a Bordeaux vineyard and the participatory approach involved various stakeholders and the use of multicriteria decision aid methods.

\section{Materials and Methods}

\subsection{Study Area and Stakeholders}

The study was carried out in a Bordeaux vineyard in the Blaye area, which is located in the northern part of south-west France and comprises 6500 ha of vine and 335,000 $\mathrm{hl}$ wine. An experimental watershed of 830 ha was identified within this area (Figure 1). The watershed is delimited by a permanent river, the Livenne, which flows into the Gironde Estuary. Viticulture represents $53 \%$ of the utilised agricultural area, with the remaining area being mainly occupied by permanent grassland and forests.

The winery of TUTIAC winegrowers was our main partner in the project. Considered to be the biggest producer of AOP wines in France, its well-known wines are Bordeaux, Bordeaux Superior, Blaye Côte de Bordeaux and Côte de Bourg. It constitutes 700 winegrowers and more than 5000 ha of vines, which produce $250,000 \mathrm{hl}$ of wine each year. The Blaye wine trade union brings together all the winegrowers of the cooperatives and the independent producers, who helped us survey the agricultural practices of winegrowers. Different Professional advisers (e.g., the Gironde Chamber of Agriculture) also contributed to the project by taking part at different stages, particularly in the modelling of new scenarios.

\subsection{Description of the Existing Viticultural Systems and Scenario Building by Combining Agroecological Practices}

Thirty eight winegrowers who apply different viticultural practices were surveyed; the majority of them (29) belong to the Tutiac winery located in the experimental 


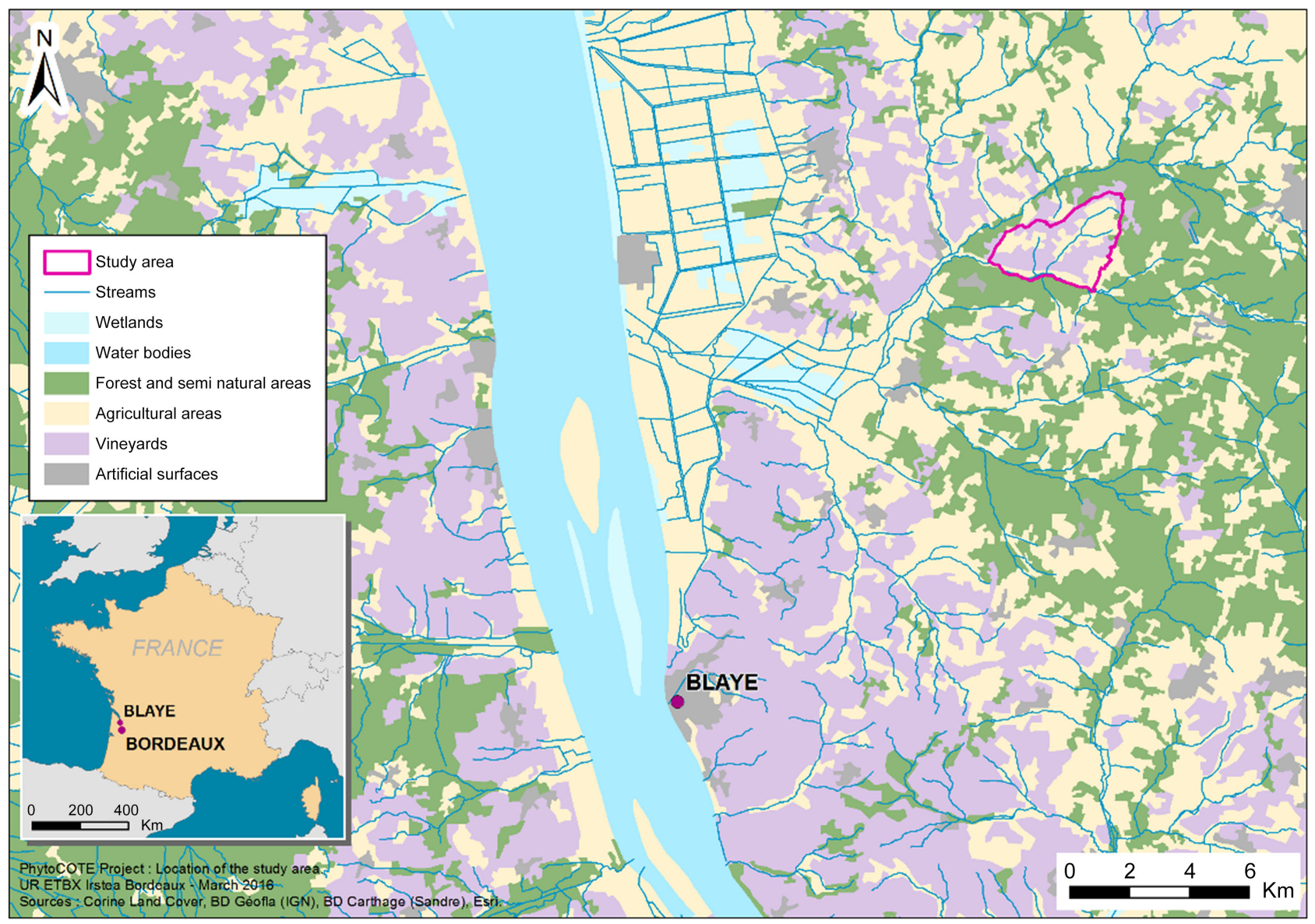

Figure 1. Location of the study area and the experimental watershed.

watershed. We also surveyed nine independent winegrowers located outside the watershed in order to explore the diversity of the existing practices. The aim of the survey was to characterise the viticultural practices adopted by winegrowers in terms of pest management and plant protection (e.g., treatments carried out, doses applied and spraying equipment used), soil management (grassing and tillage), and other vineyard operations like de-budding and pruning. All this information was used to build a technical sequence for each viticultural system.

We also identified the equipment used for the different operations-especially spraying equipment-and collected information on labour and wine production (yield and type of wine produced) in order to assess economic performance.

In the study area, the majority of the thirty viticultural systems are conventional. The development of organic viticulture (comprising eight of the systems) is on the rise due to public pressure to stop or significantly reduce the use of synthetic pesticides and consumer demand for organic wines. One of the organic vineyards has developed agroecological concepts, and is considered a success story in terms of its progressive transition towards an agroecological approach. This model was the main source of inspiration for the design of the new system in this study. 
A group of experts in viticulture and stakeholders from our study area collaborated in the design of the new viticultural systems (VS) with low pesticide use. This participatory approach to designing the viticultural systems involved four steps: 1) the identification of a set of objectives for the project, 2) the identification of a set of constraints specific to the production situation of the study area; 3 ) the design of the new systems by the working-group, based on existing practices identified in the field, and 4) the evaluation of the performance of the new systems and their comparison with existing systems.

Objectives for designing new systems and identification of the set of constraints

The results of the surveys on the viticultural practices applied in the study area, along with those of the VS performance evaluations, were used to identify the combination of best practices needed to develop the agroecological models. Viticultural systems that reconcile best environmental practices with socioeconomic performance inspired the design of the new viticultural systems. These systems adopted a holistic agroecological approach with the aim of enhancing ecosystem service and reducing reliance on pesticides.

The surveys were also a means of identifying the economic and technical constraints of changing agricultural practices. For winegrowers the main constraints were: 1) the profitability of the new systems being potentially lower than that of the current systems due to yield loss linked to pesticide reduction, and 2) the feasibility of certain techniques (e.g., mating disruption by using pheromones) in terms of costs and workload, which can increase in the new agroecological systems.

\section{Working-group for putting new systems into practice}

The working group comprised conventional and organic winegrowers from the study area, who had been surveyed for their viticultural practices and who aspire to develop more sustainable practices in the vineyard. They were either members of the winery or independent. The group also included advisors from the Tutiac winery and a group of multidisciplinary researchers from INRAE (in the fields of agronomics, economy, ecophysiology and plant protection).

These experts worked on different stages of our study, namely the identification of the study area, conducting surveys, criteria selection, and weighting and design of the new systems.

Three "realistic" scenarios for changing viticultural practices were designed. The aim was to enhance the viticultural practices adopted in each production model (conventional and organic farming). Many agroecological practices are already applied in the surveyed VS, but never together in the same vineyard; for example, the winery encourages its winegrowers to adopt agroecological practices, like planting hedges and using biocontrol agents. Some winegrowers had also invested in confined sprayers to reduce pesticide drift. Therefore, we defined three scenarios that combined these practices (Figure 2 and Figure 3). In Scenario 1 (Maximised-conv-sys), we optimised the strategies applied in the 


\section{Scenarios - Phytosanitary strategy}

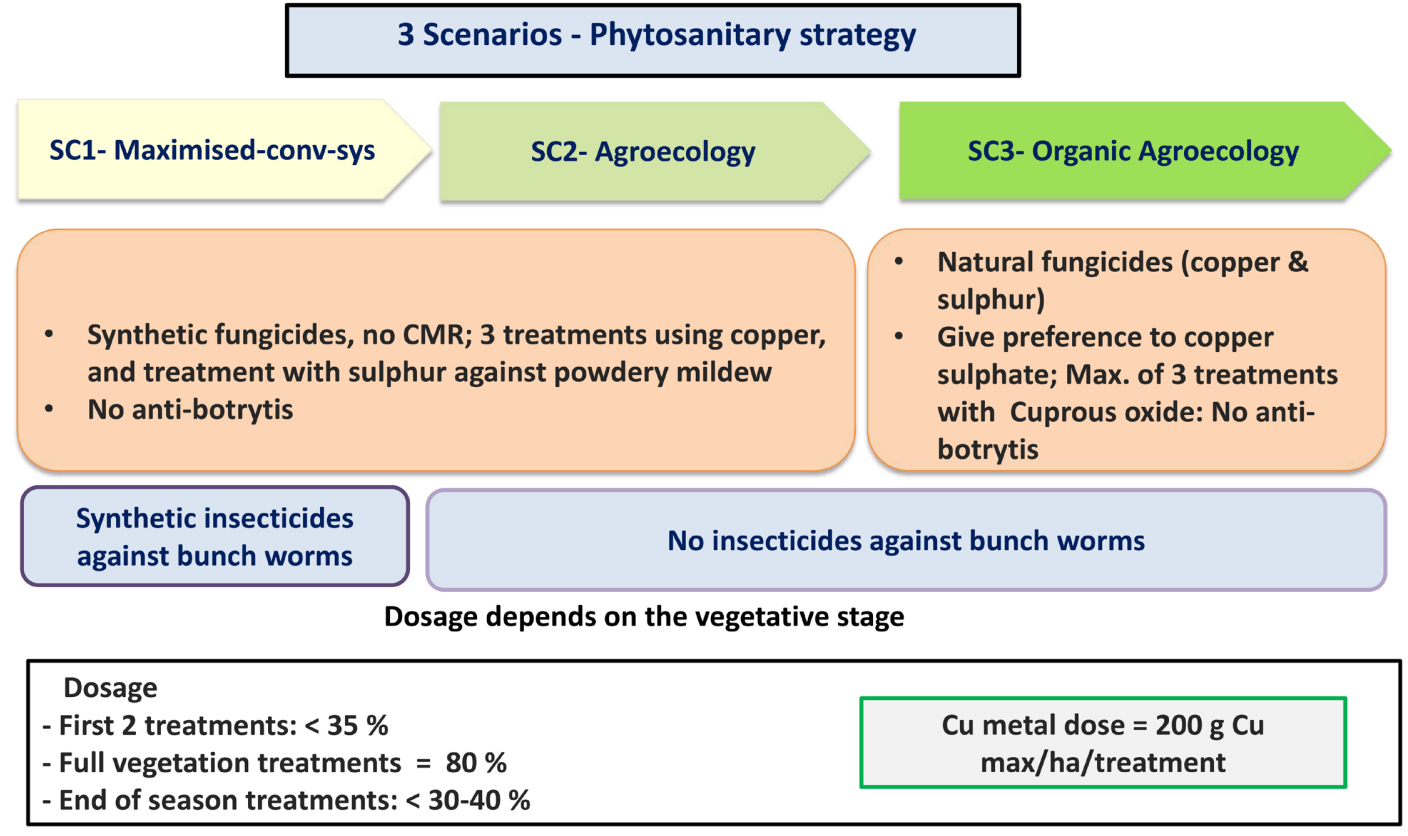

Zero Herbicide: Mechanical weeding under the row \& in the inter-row

Figure 2. Three scenarios of the sanitary strategy.

\section{Scenarios - Management of soil \& green practices}

SC1- Maximised-conv-sys

Natural grass cover $1 / 2$ interrow

Green manure $1 / 2$ inter- row Cover management: mowing

Grassy headlands

\section{SC2- Agroecology}

SC3- Organic Agroecology

Permanent green manure - mixture of species (legumes, grasses) Cover management: rolling

Grassy headlands; planting of hedges, trees, shrubs, bushes; nesting boxes; insect hotels, etc

Pruning; manual de-budding; mechanical leaf stripping and shoot trimming

Figure 3. Three scenarios of the soil and green operations management.

conventional systems. In Scenario 2 (Agroecological system) and Scenario 3 (Agroecological organic system), a set of agroecological practices were introduced to the conventional model and the organic model respectively.

In scenarios 1 and 2, the pest control strategy consisted in using chemicals to remove CMR products (Carcinogenic, Mutagenic or Toxic for Reproduction). Copper was used for the initial treatments, essentially against downy mildew, 
and sulphur for powdery mildew treatment.

In the agroecological-organic system, copper and sulfur are used to treat fungal diseases. The use of copper sulfate is recommended (lower phytotoxicity) and copper oxide (higher phytotoxicity according to advisers) is allowed depending on the weather conditions. Anti-botrytis treatments are replaced in the three systems by operations like de-budding, de-suckuring and pruning.

Insecticide against vine moths is not applied in either agroecological scenario; it is compensated for by the holistic agroecological approach adopted in these scenarios, which contributes to enhancing biodiversity and biological regulation in the vineyard. Only one insecticide against the vine moth is included in the conventional scenario, and each scenario includes a mandatory insecticide against leaf hoppers.

Pesticide dose reduction was included in the three systems with the following decision rules: in the initial treatments, the applied dose must be $35 \%$ lower than the reference dose; in the vegetative growing season, the dose must be $80 \%$ lower than the reference dose; and in the final treatments, the applied doses must be lower than $30 \%$ to $40 \%$.

In terms of soil management, a permanent vegetative cover in all vine rows was included in the agroecological systems. This involves sowing a mixture of grass and leguminous seeds and rolling in order to renew the cover and enhance the supply of organic matter in the soil. The maximised conventional system included natural grass cover in every other row, which is mechanically cut. Within-row mechanical weeding was included in all three scenarios.

In terms of agroecological features, and in addition to grass strips, scenarios 2 and 3 incorporated the planting of hedges in the vineyard (trees, shrubs and bushes), as well as features that contribute to enhancing biodiversity in vineyards; for example, providing habitats for birds and bats, which are remarkably efficient at controlling insects and can thus replace insecticides.

Other operations were included in the three systems, such as pruning, manual de-budding, mechanical leaf stripping and shoot trimming.

\subsection{Multicriteria Methods to Evaluate Viticultural System Performance}

We chose the ELECTRE methods in association with a GIS, because they have already been used by the team in the study area to model the risks of pesticide contamination of surface water. The methods are well-suited to the definition of quantitative and qualitative criteria, making it possible to organise systems into different categories or according to their performance level.

\subsubsection{ELECTRE Methods for MCDA}

ELECTRE methods (Elimination and Choice Expressing the Reality) were developed for multiple criteria Decision Aiding (MCDA) by Roy [31] [32] and Almeida-Dias et al. [33] [34]. 
These methods are based on outranking relationships which aim to compare each pair of alternatives in a comprehensive way. The alternative "a" represents the component contributing to the decision, which, in our study, comprises the viticultural systems (combination of agricultural practices applied to the vine).

The outranking procedure depends on the activity; i.e., choosing, ranking or sorting [35]. Ranking involves comparing each alternative with other alternatives for each criterion. Alternatives are ranked from best to worst with possible ex equo (ELECTRE III). For sorting, a set of categories is a priori defined; each alternative is considered independently from the other in order to determine which category it should be assigned to. Each one is compared with a set of virtual alternatives which represent reference values created to define each category (ELECTRE Tri-C).

The criterion "g" is a judgment factor used to measure and estimate the performance of the viticultural systems. ELECTRE methods make it possible to take into account qualitative and quantitative criteria, heterogeneous criteria and conflicting criteria. The weight assigned to each criterion is also considered. An incomparable or equal alternative is accepted. Discrimination thresholds of preference $(p)$ and indifference $(q)$ are used to build outranking relationships, and they take into account the imperfect character of the evaluation of alternatives. Figure 4 explained the principle of the outranking method.

In this study, we first assessed the performance of existing viticultural systems using the ELECTRE Tri-C model in order to assign each system to one of the four pre-defined performance categories based on a set of socio-economic and environmental criteria. In the second step, we assessed the performance of the three scenarios of the systems we had designed by using the same categories. After that, we ranked all the systems within the same category of performance, in order to identify the best strategies for reducing pesticide use while maintaining high profitability. The methodology adopted for the implementation of MCDA is explained in Figure 5.

\subsubsection{Choice of Criteria and Their Indicators for the Assessment of Viticultural System Performances}

The aim of this study was to determine the diversity of viticultural practices

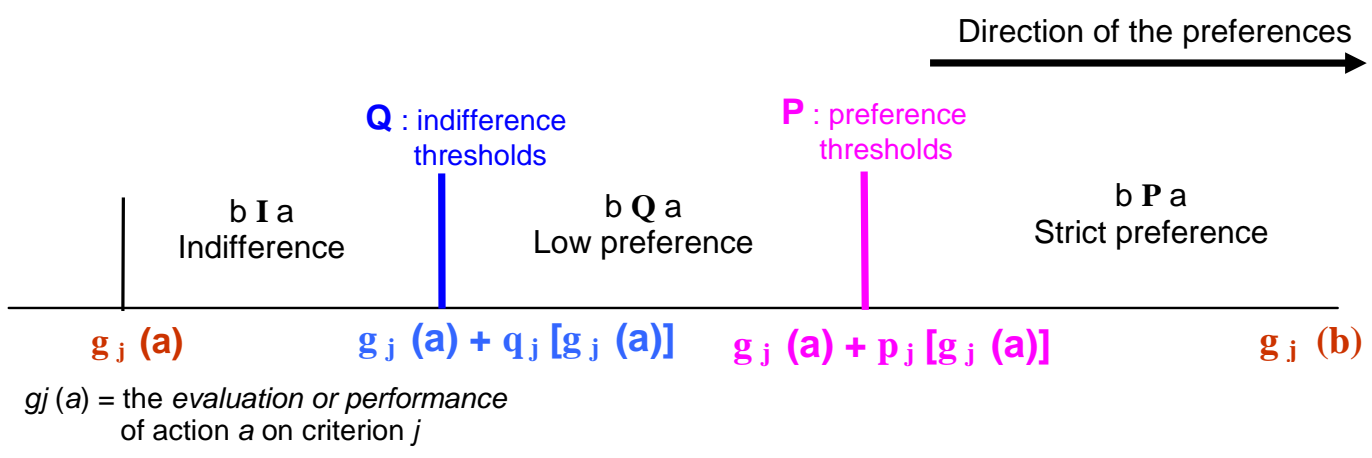

Figure 4. The general principle of the outranking method [29]. 


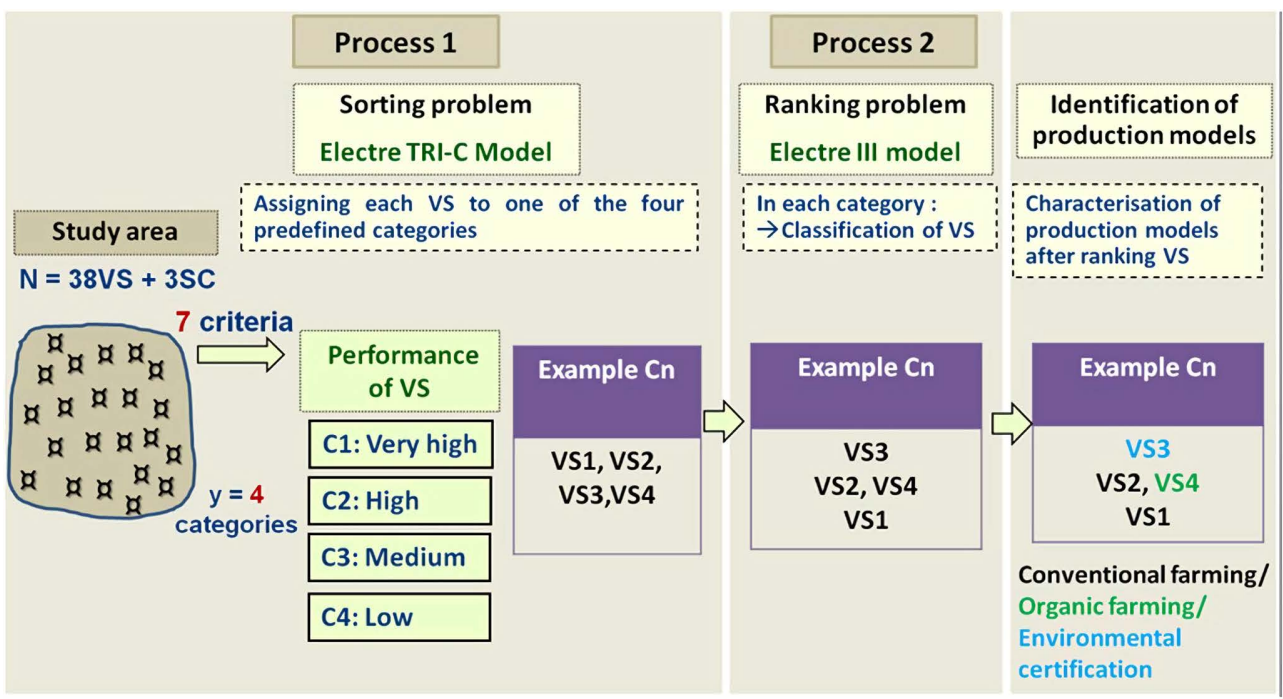

Figure 5. Methodology for MCDA modelling, using ELECTRE methods.

adopted by the winegrowers in the field, and to assess their environmental and socio-economic performance in order to identify those which gave the best overall performance. We met socio-economic actors in the field (winegrowers and professional advisers). Together, we chose seven of the most representative criteria to be used for evaluating the real systems and then for designing new production scenarios (Table 1). Each criterion chosen in the outranking multicriteria methods explained part of the result; consequently, the criteria were limited in number and the relevant one selected. They were also weighted (Section 2.3.3).

\section{- Economic performance}

Economic performance was defined as profitability (CR1. REN) based on the margin that we proposed for comparing the different viticultural systems. The following formula was used:

Margin $=$ Fixed total revenue $(€ /$ ha $)-$ Input costs $($ pesticides, seeds and fuel $)$ - mechanisation cost - labour cost (manual and mechanical)

To calculate this margin, we made the following choices:

1) We assumed that for all the viticultural systems, the yield fixed by the $A_{O P}{ }^{1}$ label was obtained; the performance of a viticultural system is assessed for "normal" climate conditions and "normal" biotic pressures: the aim was to compare the practices of the systems and not the profitability of the vineyards.

2) Given that the yield is fixed, we took into account a database reference of six fixed total revenue per hectare. The revenue amount depends on the practices carried out on the vine, like pruning or the removal of suckers from vinewood and of the cover crop in the inter-row. According to different information provided by winegrowers, the total revenue can range from 5400 euros/ha for basic systems to 8000 euros/ha for organic systems (Appendix 1).

${ }^{1}$ Appellation d'origine protégée. 
Table 1. List of criteria for the assessment of viticultural system performances.

\begin{tabular}{|c|c|c|}
\hline Performance & Criteria & Indicators \\
\hline Economic performance & $\begin{array}{l}\text { CR1 (REN) Profitability of } \\
\text { viticultural system (Quantitative) }\end{array}$ & Margin of viticultural system ( $€ /$ ha $)$ \\
\hline \multirow{4}{*}{$\begin{array}{l}\text { Environmental } \\
\text { performance }\end{array}$} & $\begin{array}{l}\text { CR2 (PPS) Pesticide pressure. } \\
\text { (Quantitative) }\end{array}$ & TFI: Treatment frequency Index \\
\hline & $\begin{array}{l}\text { CR3 (IRE) Risk of ecotoxicity. } \\
\text { (Quantitative) }\end{array}$ & $\begin{array}{l}\text { IRTE*: toxicity risk indicator for the } \\
\text { environment }[36]\end{array}$ \\
\hline & $\begin{array}{l}\text { CR4 (PAE) Agroecological prac- } \\
\text { tices (Qualitative) }\end{array}$ & $\begin{array}{l}\text { - Cover cropping in the inter-row } \\
\text { - Weed management } \\
\text { - Agroecological measures (buffer } \\
\text { strips; hedges, etc.) Use of } \\
\text { biocontrol method (e.g., birds (tits) } \\
\text { or bats against grape worms) }\end{array}$ \\
\hline & $\begin{array}{l}\text { CR5 (PUL) Pesticide spray drift } \\
\text { (Qualitative) }\end{array}$ & Spray equipment \\
\hline \multirow[b]{2}{*}{ Social performance } & $\begin{array}{l}\text { CR6 (TRA) workload } \\
\text { (Quantitative) }\end{array}$ & $\begin{array}{l}\text { Labour time required per hectare for } \\
\text { manual and mechanical operations }\end{array}$ \\
\hline & $\begin{array}{l}\text { CR7 (SYS) System complexity } \\
\text { (Qualitative) }\end{array}$ & $\begin{array}{l}\text { - Number of mechanical and manual } \\
\text { operations } \\
\text { - Dispersion of parcels }\end{array}$ \\
\hline
\end{tabular}

3) We used standard references in the computation process; for example, those from the $\mathrm{BCMA}^{2}$ database for the calculation of mechanical costs, taking into consideration standard equipment, workload and energy consumption.

\section{- Environmental performance}

The environmental performance of each viticultural system was assessed using four criteria: pesticide pressure, pesticide ecotoxicity, the agroecological practices adopted in the vineyard and pesticide drift.

Pesticide pressure (CR2. PPS) was evaluated using the treatment frequency index (TFI) calculated for each pesticide using the following formula:

$$
\text { Pesticide TFI }(\text { per hectare })=\frac{\text { Applied dose } \times \text { treated surface area }}{\text { Registered dose } / \text { total surface }}
$$

The overall TFI for each viticultural system was evaluated by calculating the sum of TFI for all the pesticides, which were weighted according to the fraction of treated surface.

Pesticide pressure indicates the level of reliance on pesticides, but not the impact of pesticide use on the environment. Therefore, we chose to assess the ecotoxic impact of the pesticides used in the vineyard (CR3. IRE) using an environmental toxicity risk indicator (IRTE). This criterion was developed and calculated by researchers of the Mediterranean Agronomic Institute of Montpellier.

IRTE evaluated the toxicity of pesticides on non-target living organisms (i.e., terrestrial invertebrates, birds and aquatic organisms) and takes into account the ${ }^{2}$ Bureau Commun de Machinisme Agricole; French organisation for agricultural machinery. 
physico-chemical proprieties of molecules (i.e., mobility, persistence in the soil and bioaccumulation) [36]. It is calculated using the following formula:

$$
\text { Pesticide IRTE }=[1.75 \times(T+O)+A+M+P+B+1]^{2}
$$

where:

$T=$ acute toxicity rating for terrestrial organisms (bees).

$O=$ acute toxicity rating for birds.

$A=$ acute toxicity rating for aquatic organisms.

$M=$ mobility of the active substance.

$P=$ persistence of the active substance.

$B=$ bioaccumulation of the active substance.

This indicator is based on the ratio toxicity/exposition identified for each species (Directive 91/414/CEE; [36]; Appendix 2).

IRTE was calculated for the viticultural systems as follows:

$$
\begin{gathered}
\text { IRTE Parcel }=\sum[\text { pesticide IRTE } \times \text { TFI } / \text { ha } \times \text { treated surface }(\text { ha })] \\
\text { IRTE VS }=\sum \text { IRTE parcel }
\end{gathered}
$$

Agroecological practices (CR4 PAE) contribute to preserving biodiversity and reducing the use of chemicals (pesticide and fertilisers). The present study focused on the following practices already adopted by some winegrowers:

- Grass cover in the inter-row: natural/sowed, total/partial.

- Vine row management: chemical/mechanical weeding.

- Agroecological features (AS): grass strips, flowering strips, hedges, insect hotels, nest boxes.

- Use of biocontrol agents, comprising natural (plant, animal and mineral) substances used for plant protection. We used the official list of biocontrol agents published by the French Ministry of Agriculture, Food and Forestry. This criterion is assessed by calculating the treatment frequency index of biocontrol agents.

The criterion "Agroecological practices" comprises several qualitative components, which were each assigned a rating in order to integrate the criterion into the model. Such rating was only attributed to qualitative criteria and served to distinguish the different systems for each criterion.

The potential for spray drift (CR5. PUL) was assessed by classifying the spray equipment used in the vineyard according to its capacity for reducing pesticide losses to the environment. This classification was based on a study carried out by the French Institute of Vine and Wine (IFV), which assessed the performance of different types of spray equipment. The least efficient equipment was found to be the air blast sprayer and the air blower sprayer. The recovery sprayer and the confined sprayer is the best equipment for reducing pesticide drift.

A rating was assigned to each category (Appendix 3).

\section{- Social performance}

Social performance was assessed using two criteria. The workload (CR6 TRA) 
was calculated for each technical operation (mechanical and manual) using the following formula:

$$
\begin{aligned}
\text { TRA }= & {[\text { number of hours }(\text { mechanical operations })} \\
& \left.\left.\times 6.4^{*} \text { number of hours (manual operations }\right)\right]
\end{aligned}
$$

${ }^{*}$ ration between the number of hours for manual operations and mechanical operations.

The other criterion was the complexity of the system (CR7. SYS), which takes into consideration the number of mechanical and manual operations, as well as the distance from the parcels to the main vineyard buildings. Appendix 4 shows the rating assigned to each category.

The ELECTRE model input data is shown in the table called "Performance Matrix" (Appendix 5).

\subsubsection{Model Setting: ELECTRE III and ELECTRE TRI-C}

Criteria weighting was conducted collaboratively by four winegrowers (two conventional and two organic), three advisors in viticulture practices and six researchers (agronomists and economists from INRAE and Bordeaux Science Agro), using the SFR method [37].

Details of the method are given in Appendix 6. A "playing card" was assigned to each criterion, the cards were ranked, and the importance of a given criterion in comparison to the following one (white cards) was determined. The number of times the most important criterion dominated the less important one was also determined. Ten "players" participated and we summarised the outcomes. SRF software was then used to obtain the final weights (Table 2).

By using discriminating thresholds in the models, it is possible to correct the imperfect data used for calculating the performance of different actions (in this case, the viticultural systems) per criteria. It is also possible to determine a preference for a certain action over the others, or even over a reference action that characterises each of the performance level categories [34].

A strict preference threshold $\left(p_{g}\right)$ and an indifference threshold $\left(q_{g}\right)$ were determined for each criterion (Appendix 7). The former corresponds to a situation in which there are clear and positive reasons for being in favour of one of the two actions; the latter corresponds to a situation where there are clear and positive reasons for equivalence between the two actions [35].

The thresholds are calculated by determining $\alpha$ and $\beta$ coefficients:

$$
\text { Threshold }\left(g_{j}(a)\right)=\alpha \times g_{j}(a)+\beta ;
$$

$g_{j}(a)$ : the performance of the action (a) for criterion $j$.

For the ELECTRE Tri-C model it is necessary to establish reference values for each predefined category. We based these on statistical values $\left(1^{\text {st }}, 2^{\text {nd }}\right.$ and $3^{\text {rd }}$ quartiles) for quantitative criteria, keeping the same distance between the categories (Table 3). 
Table 2. Assigned weights to the criteria of evaluation using SRF software.

\begin{tabular}{lcc}
\hline \multicolumn{1}{c}{ Criteria } & Code & Weights (\%) \\
\hline CR1: Profitability & REN & 22 \\
CR2: Pesticide pressure & PPS & 20 \\
CR3: Risk of ecotoxicity & IRE & 15 \\
CR4: Agroecological practices & PAE & 13 \\
CR5: Spray quality & PUL & 13 \\
CR6: Workload & TRA & 10 \\
CR7: System complexity & SYS & 7 \\
\hline
\end{tabular}

Table 3. Reference value of each category for all criteria of evaluation.

\begin{tabular}{cccccccc}
\hline Categories & REN & PPS & IRE & PAE & PUL & TRA & SYS \\
\hline Very high performance & 3000 & 10 & 3000 & 53 & 8 & 230 & 12 \\
High performance & 2400 & 13 & 4000 & 38 & 6 & 250 & 20 \\
Medium performance & 1900 & 15 & 5500 & 23 & 4 & 270 & 28 \\
Low performance & 1400 & 17 & 7000 & 8 & 1 & 300 & 36 \\
\hline
\end{tabular}

\section{Results}

The survey results revealed that the winegrowers are careful with respect to the maximum number of treatments in a crop year, and they take into account impacts on human health and the environment, as well as the cost of pesticides. The most important decision criteria that should be dealt with are: the climate, the vineyard observations, the agricultural warnings and the advice.

\subsection{Multicriteria Assessment of Existing VS}

Appendix 8 presents the results of the assessment of the 38 viticultural systems using ELECTRE Tri-C. The model assigned each VS to one of the four predefined categories of performance. The production models were characterised after modelling.

One viticultural system (SV59) was assigned to the category "very high performance". This is an organic VS in which a holistic agroecological approach is applied.

The other organic VS, as well as a certified system (SV67) and five conventional systems, were assigned to the "high performance" category. The second certified system (SV 33) was assigned to the "medium performance" category associated with conventional systems.

Profitability and pesticide pressure had the highest weight in the multicriteria analysis (42\%). The variability of these criteria for each production model was analysed to gain a better understanding of the results (Figure 6 and Figure 7).

Organic systems have a higher gross margin per hectare, which is related to higher total revenue than in conventional systems. Basing on the total revenue 


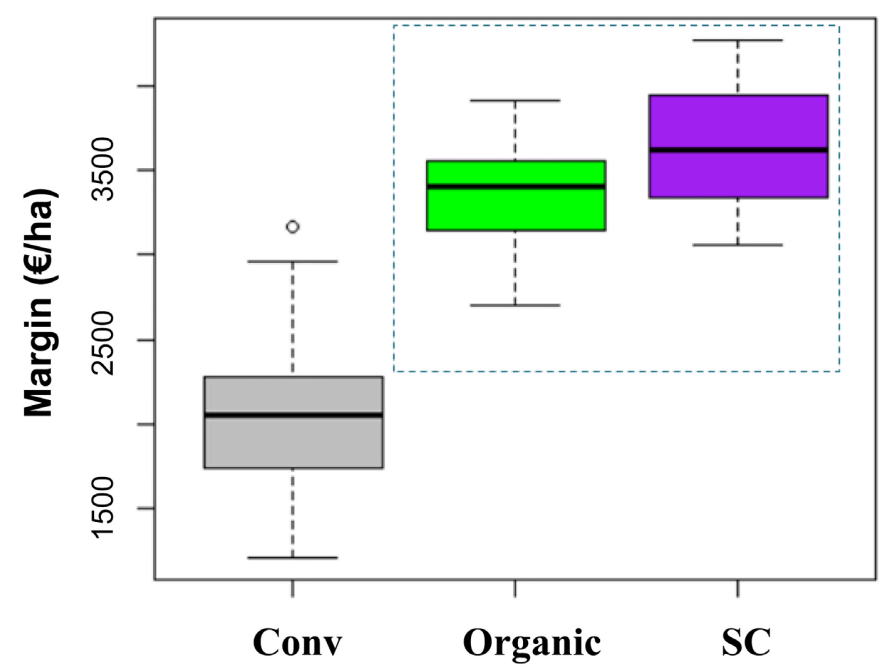

Figure 6. Variability of the profitability.

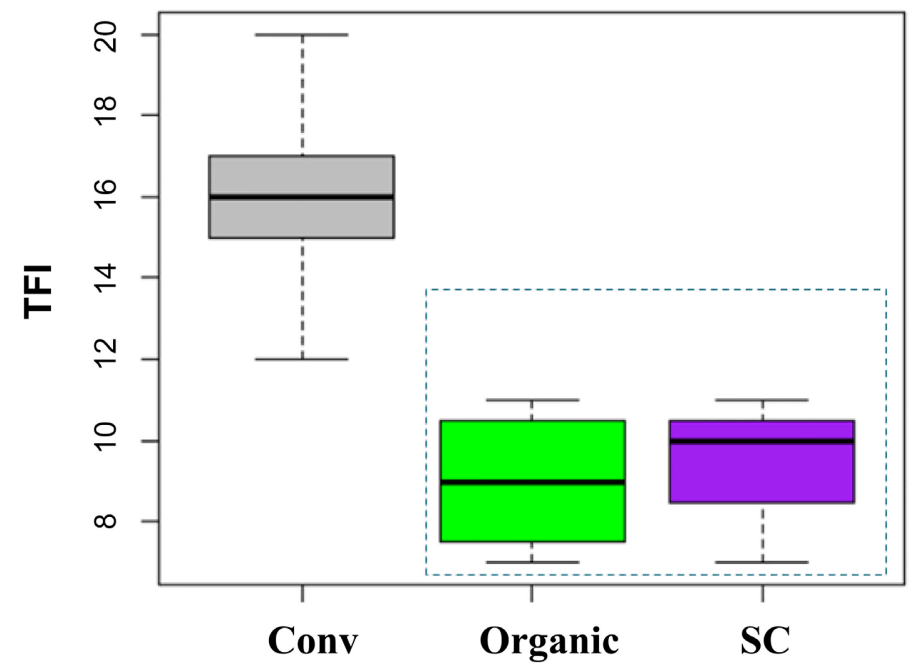

Figure 7. Variability of the pesticide pressure.

references adopted in this study (Appendix 1), systems in organic farming are remunerated $8000 € / \mathrm{ha}$, while in conventional farming the mean total revenue value is $6000 € / \mathrm{ha}$. Such higher total revenue compensates for the high costs of organic systems, which are about $300 € /$ ha higher.

Moreover, organic systems have a low TFI compared to conventional systems (mean TFI is 9 for organic systems versus 16 for conventional systems).

Organic VS reduce pesticide use and have high economic performance, which explains the high overall performance in the MCDA analysis.

Figure 8 shows the values for pesticide pressure (PPS) and for ecotoxicity (IRE) for each viticultural system. The relationship between the two criteria shows that the organic VS-which have the lowest TFI-are also highly toxic to the environment due to the treatments applied, namely copper. Depending on its form (copper sulphate, copper hydroxide or copper oxide), copper is known 


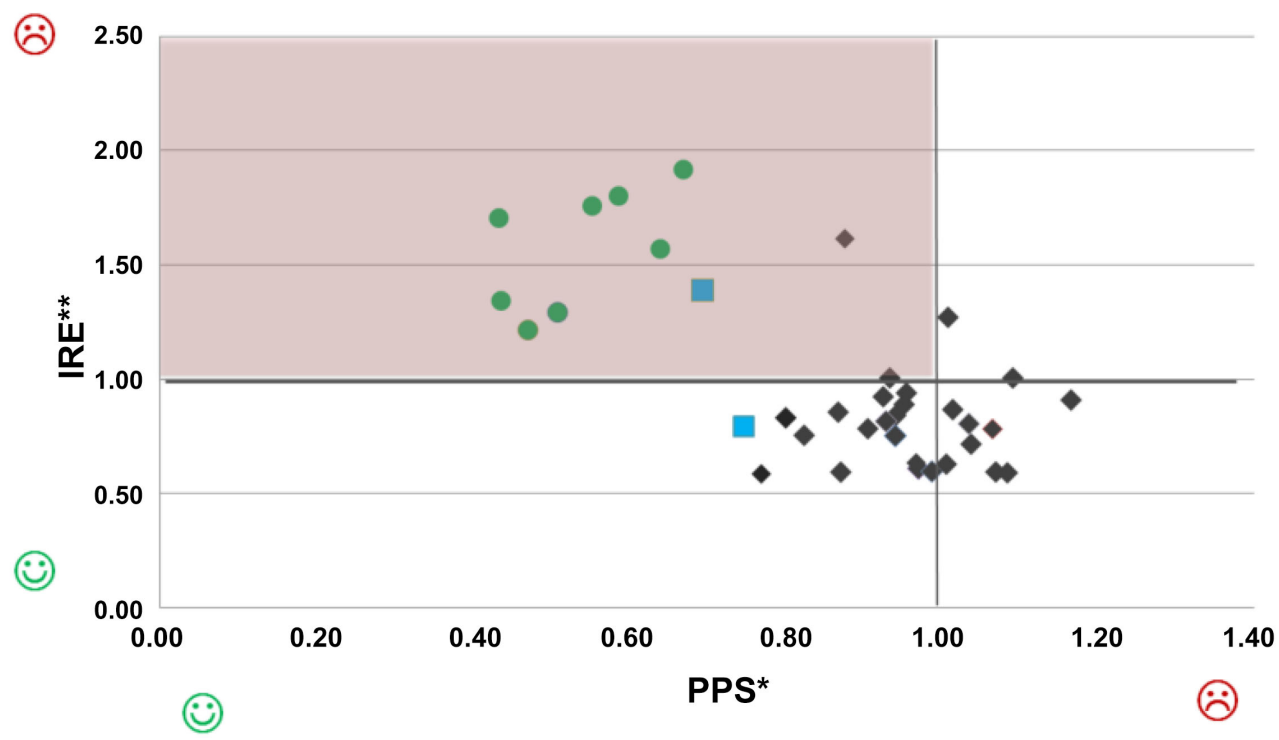

Figure 8. Relationship between the pesticide pressure and the ecotoxicity of pesticides. ${ }^{*}$ normalisation/standard regional TFI (16.9); ${ }^{* *}$ normalisation/mean value of the criterion IRE.

to have harmful effects on the environment [38] [39]. In conventional systems, the pressure is higher, but the ecotoxicity of organic pesticides is lower than inorganic pesticides with copper.

\subsection{Multicriteria Assessment Scenarios and Comparison with Existing Systems: ELECTRE Model Results}

Table 4 presents the results of the sorting scenarios and ranks all the systems with in each performance category. The agroecological systems in organic viticulture (SC3) and conventional viticulture (SC2) were assigned to the very high performance group, being ranked first and second respectively.

The maximised conventional system (SC1) was assigned to the high-performance category in first place along with the organic VS (VS 42).

The MCDA model ranked the agroeco-organic system (SC3) as being the most efficient. In terms of economic performance, this system had the highest viticultural margin per hectare (the weight of this criteria REN explains $22 \%$ of the ranking). This result can be explained by the difference in the total revenue between SC3 and the conventional systems (current systems, SC1 and SC2). Compared to the organic systems, whose margin is calculated using the same total revenue reference, SC3 slightly reduces costs. Furthermore, SC3 improves general environmental performance by reducing pesticide pressure (PPS represent $20 \%$ of the weight). In this system, the pesticide drift is also reduced due to the use of an efficient sprayer, and agroecological practices are maximised.

The agroecological system (SC2) was ranked second in the category "very high performance". In particular, this system reduced costs, especially those related to pesticide use (Figure 9 and Table 5). Out of the three simulated systems (SC1, 
Table 4. Results of sorting real VS and scenarios, using Electre TRI-C model and their ranking in each category of performance using Electre III models.

\begin{tabular}{|c|c|c|c|}
\hline Categories & Performances & Viticultural systems & Number \\
\hline $\mathrm{C} 1$ & Very high performance & $\begin{array}{c}\text { SC3 } \\
\text { SC2 } \\
\text { VS59 }\end{array}$ & $3(7.3 \%)$ \\
\hline $\mathrm{C} 2$ & High performance & $\begin{array}{c}{[\mathrm{SC} 1, \mathrm{VS} 42]} \\
{[\mathrm{VS} 09, \mathrm{VS} 38, \mathrm{VS62}]} \\
{[\mathrm{VS} 40, \mathrm{VS} 56, \mathrm{VS} 61, \mathrm{VS67}]} \\
{[\mathrm{VS} 07, \mathrm{VS} 55]} \\
{[\mathrm{VS} 54, \mathrm{VS} 39]}\end{array}$ & $13(31.7 \%)$ \\
\hline $\mathrm{C} 3$ & Medium performance & $\begin{array}{c}\text { VS36 } \\
\text { VS63 } \\
\text { [VS32, VS58, VS65] } \\
\text { [VS33, VS50, VS53] } \\
{[\text { VS10, VS60, VS66, VS68] }} \\
{[\text { VS05, VS52] }} \\
\text { VS04 } \\
\text { VS11 } \\
\text { [VS08, VS31] } \\
\text { [VS18, VS57] } \\
\text { VS51 } \\
{[\text { VS23, VS64] }}\end{array}$ & $23(56 \%)$ \\
\hline $\mathrm{C} 4$ & Low performance & $\begin{array}{l}\text { VS22 } \\
\text { VS34 }\end{array}$ & $2(5 \%)$ \\
\hline
\end{tabular}

Organic systems/Systems with environmental certification/Conventional systems.

Table 5. Profitability (SV margin) and mainly production costs for the existing conventional and organic systems \& 3 scenarios.

\begin{tabular}{ccccccc}
\hline & & \multicolumn{5}{c}{ Cost details } \\
\hline ( $€$ /ha) & $\begin{array}{c}\text { Economical } \\
\text { margin }\end{array}$ & $\begin{array}{c}\text { Mechanis. } \\
\text { costs }\end{array}$ & $\begin{array}{c}\text { Energy } \\
\text { costs }\end{array}$ & $\begin{array}{c}\text { Pesticide } \\
\text { costs }\end{array}$ & $\begin{array}{c}\text { Labour } \\
\text { costs }\end{array}$ & Total costs \\
\hline 30 Conv VS (average) & 2076 & 611 & 258 & 590 & 2115 & 3574 \\
8 Bio VS (average) & 3354 & 799 & 313 & 322 & 2416 & 3850 \\
SC1 Conv-Max & 3062 & 919 & 330 & 458 & 2205 & 3913 \\
SC2 Agroeco-conv & 3617 & 760 & 213 & 372 & 2038 & 3383 \\
SC3 Agroeco-Bio & 4274 & 921 & 309 & 359 & 2138 & 3726 \\
\hline
\end{tabular}

SC2 and SC3), the lowest economical margin was obtained by the maximised conventional system (SC1), because of the total revenue difference (Appendix 1) and high total costs, such as pesticides and energy.

\section{Discussion}

Several multicriteria methods for decision aiding (MCDA) were explored, including the MASC and DEXiPM methods which could not be applied in this study. 


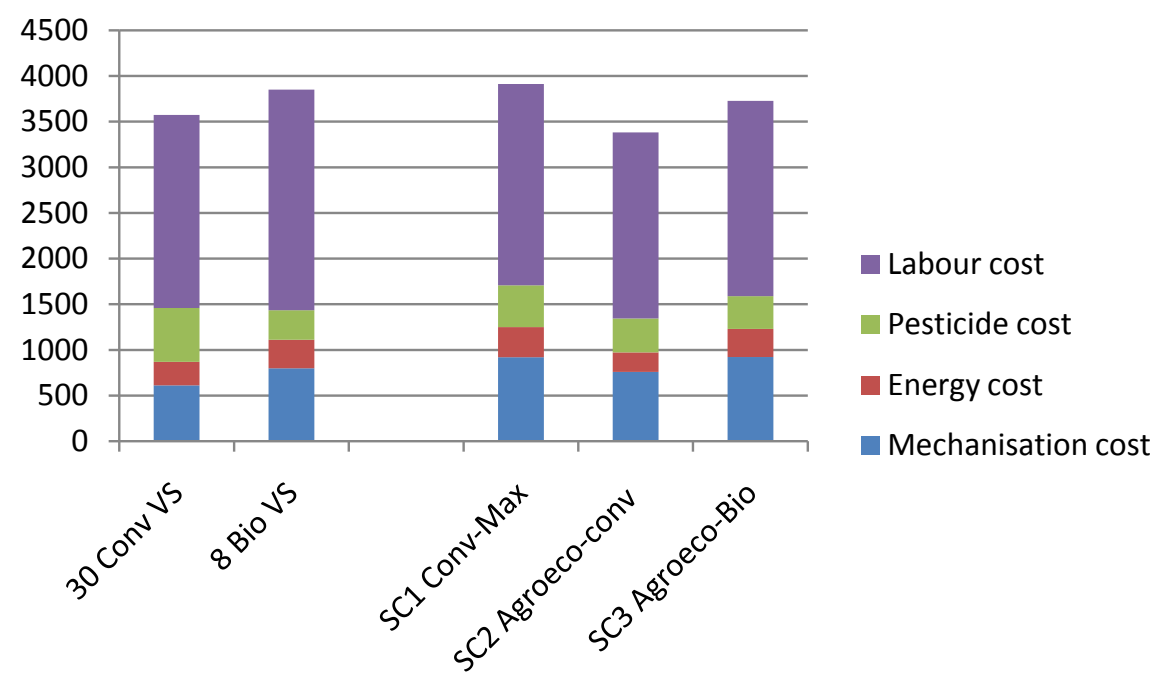

Figure 9. Comparison of operational costs between different systems of production (conventional and bio) in three scenarios.

DEXiPM models (DEXiø software) [25] perform a qualitative hierarchical aggregation of the criteria based on decision trees. All the components of the hierarchical structure (called "attributes") are defined by qualitatively grouping the values (e.g., high, medium and low). The aggregations are performed for each attribute with "utility functions" specified in tables completed with 'IF-THEN' aggregation rules [25].

The DEXiPM model has been applied to viticulture and it proposes a range of criteria for the three dimensions of sustainability (environmental, economic and social) [40].

This method could not be applied here as some criteria and indicators were difficult to evaluate in our study; for example, the criteria which are calculated from the description of the environment (soil and climate), and which must be estimated on a field scale. In addition, it was not necessary to assess overall sustainability in our study, and the partial use of such models (the selection of criteria and indicators of interest) was irrelevant and could have compromised their performance and results. However, these models were still useful for helping select some evaluation criteria.

The ELECTRE and PROMETHEE multicriteria decision aid methods have been widely used and approved for decision making in agriculture and environmental science [29] [30] [33] [34] [35].

The general methodology developed using ELECTRE methods, and the results obtained here, have the main advantage of being part of a holistic approach, with criteria not already set within a pre-established model, but defined according to the needs of the study. The proposed and tested scenarios can be realistically applied in vineyards in any winegrowing region, if adaptations are made to the pedo-climatic context and economical benchmarks.

In the EcoViti project, the method described by Lafon et al. [41] and Metral et 
al. [42] for prototyping new vineyard cropping systems is based on expert knowledge, conceptual modelling and field experiments carried out within a coordinated network of experimental platforms. During the six years of experiments, the DEPHY EXPE Mediterranean belt network designed, experimented on and assessed two innovative prototypes of grapevine farming systems with low pesticide inputs: one was based on integrated protection management, and the other used biocontrol solutions. The study was mainly orientated towards reducing pesticides, but, in contrast to our study, it did not really integrate agroecological practices and holistic scenarios.

\section{Economic performance}

According to Doody et al. [43], a "good indicator" should simplify the assessment of a studied system. Assessing the economic performance of viticultural systems is highly complex due to many factors; for example, the diversity of marketing strategies and the impact of weather and climate conditions on yield, which can vary considerably from one year to another.

In this study, we chose to evaluate economic performance by calculating the margin of the viticultural systems based on a fixed yield (AOP yield). This hypothesis can notably be contested when applied to organic viticulture, in which the control of pests and diseases tends to be more difficult. However, the strategy adopted in the study area by organic winegrowers involves the use of different copper compounds (copper sulphate, copper hydroxide or copper oxide) depending on climate conditions. In addition, the application of low doses of copper within short intervals can improve pest control and reduce yield losses; this would require the winegrower to monitor the growth and health of the vine in order to regulate the copper dosage.

Given that the yield is fixed, we used a database reference of six fixed total revenues per hectare. Each viticultural system was linked to one total revenue reference when the crop practices were the same in all systems, or to more than one total revenue reference weighted by the treated surface when the crop practices were heterogeneous. A significant increase in organic production in the future could entail a reduction in gross product per ha; however, because organic wine producers often market their own wine themselves, such a drop would be mitigated as a result of higher supply.

When calculating the margin of the viticultural systems, we did not take into account vinification costs and the sales and marketing strategy for the final product applied by each winegrower. In fact, the aim of this study was to assess the impact of the crop practices in the field on the viticultural margin of the systems based on standard references, and not to compare the real economic performance of the vineyards.

On this basis, we may have underestimated the margin of independent winegrowers who sell bottled wine directly.

\section{Environmental performance}

TFI and IRTE were calculated to assess pesticide pressure and environmental 
impact. The results showed that both the VS with environmental certification and organic VS significantly reduced the level of pesticide use; nevertheless, the toxicity of the treatments applied in these systems was higher than the conventional chemicals used in the other systems. This result is explained by the high toxicity of the copper used in these VS systems, compared to conventional fungicides.

However, the IRTE is a theoretical indicator which is used to assess the ecotoxicity of treatments without taking into account soil characteristics, like acidity and organic matter content. These factors influence the soil adsorption of copper $\left(\mathrm{Cu}^{2+}\right)$ in a clay-humic complex or in organic matter; the adsorption of copper $\left(\mathrm{Cu}^{2+}\right)$ could reduce the toxicity of copper-based treatments. More research is required to explain this aspect, which is the subject of a future research project of the consortium.

Santiago-Brown et al. [44] provide a short list of environmental indicators that can be used to assess agricultural systems. These indicators were proposed by 83 top-level executives sourced from wine-grape growing organisations from New World wine-producing countries. The executives also owned vineyards, and when making their selection they took the everyday vineyard management practices into account.

Soil quality and biodiversity were at the top of the list of environmental indicators selected by this group. Developing an agroecological approach involves adopting practices that enhance biodiversity and provide ecological services such as biological pest control, nutrient cycling, and water and soil conservation [45].

Practices which will ensure a functional biodiversity include reducing the use of pesticides and especially insecticides, eliminating herbicides and instead growing cover crop and thus improving soil quality, planting trees and hedges, and providing habitat for natural enemies. Assessing the impact of these practices was difficult. In the surveyed systems, only one viticultural system (SV59) had adopted a holistic agroecological approach, and it was assigned to the "high performance" category. Biodiversity monitoring is carried out on this vineyard in other research programmes in order to study the relationship between agroecological practices and biodiversity.

In terms of virtual scenarios, biodiversity cannot be evaluated in an ex ante assessment. However, if these scenarios were adopted in the field, such an assessment would be possible.

\section{New scenarios integrating agroecological practices}

Two options were explored for the design of the new scenarios: 1) designing realistic scenarios which take into account innovative practices applied in the field, but not applied simultaneously in the same place, and 2) creating systems by significantly modifying existing ones; for example, using grape varieties resistant to downy and powdery mildew. Experts in this field pointed out that current regulation limit the presence of resistant grape varieties in the blend to 5\% of the wine, which is not enough to reduce pesticide use and its impact on the 
environment. In addition, these grape varieties require a minimum of two to three anti-mildew treatments in the Atlantic area. We therefore retained the first option.

Conditions for the success of a transition towards agroecology in viticulture

Adopting agroecological practices, and especially herbicide removal, in viticulture often results in an increase in workload due to the increase in complexity of vineyard operations [46]. Practices which exclude the use of herbicides are also known to be energy intensive, and the necessary vineyard observations could be an obstacle to adopting such cultivation methods for large vineyards.

Our study confirms an increase in workload in non-conventional systems; in organic VS the workload is heavier than in conventional systems (Figure 10) as the number of interventions in the vineyard increases due to mechanical weeding (both inter-row and within row) and the frequency of phytosanitary treatments. Figure 10 also shows that the variability of the work is higher in organic VS; in fact, viticultural practices are more homogeneous in conventional systems, especially in systems belonging to a winery, which provides recommendations and guidance. The workload in the agroecological scenarios is not much greater than that of the conventional ones. Nevertheless, the observation time required to regulate biological processes in the vineyard was not taken into account: this can be a significant obstacle to the application of this cultivation method over a large area.

In terms of energy use in both agroecological scenarios, the permanent inter-row grassing strategy involves simply rolling the grass rather than mowing it; this practice already exists in some vineyards. Keeping a grass cover in the inter-rows reduces soil tillage and in turn energy use.

The farm size is another important factor to take into account when making the transition to an agroecological system. In fact, viticultural systems in which

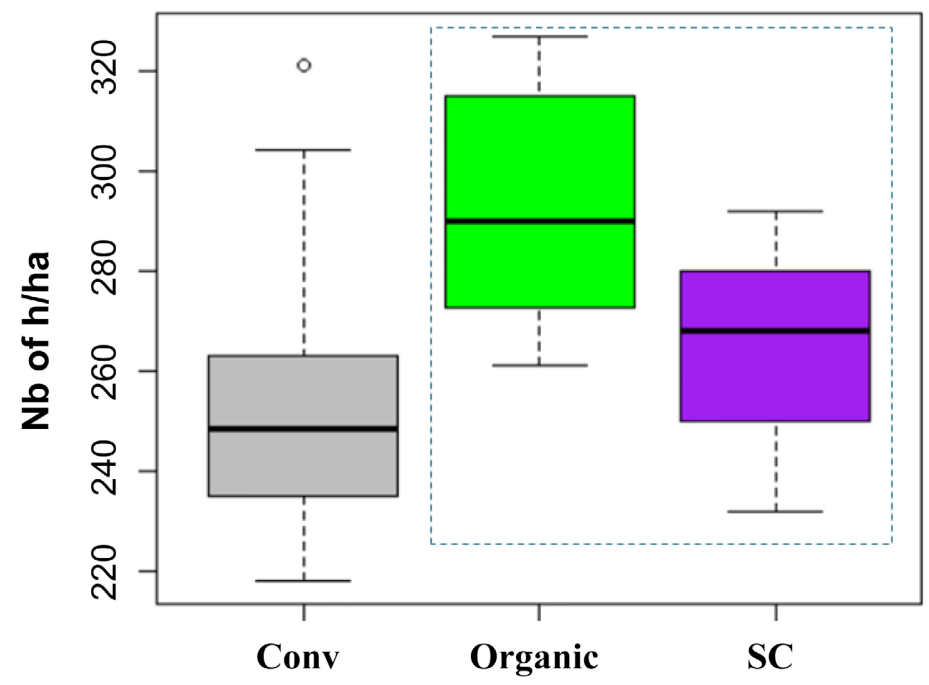

Figure 10. Variability of workload (CR7. TRA). 


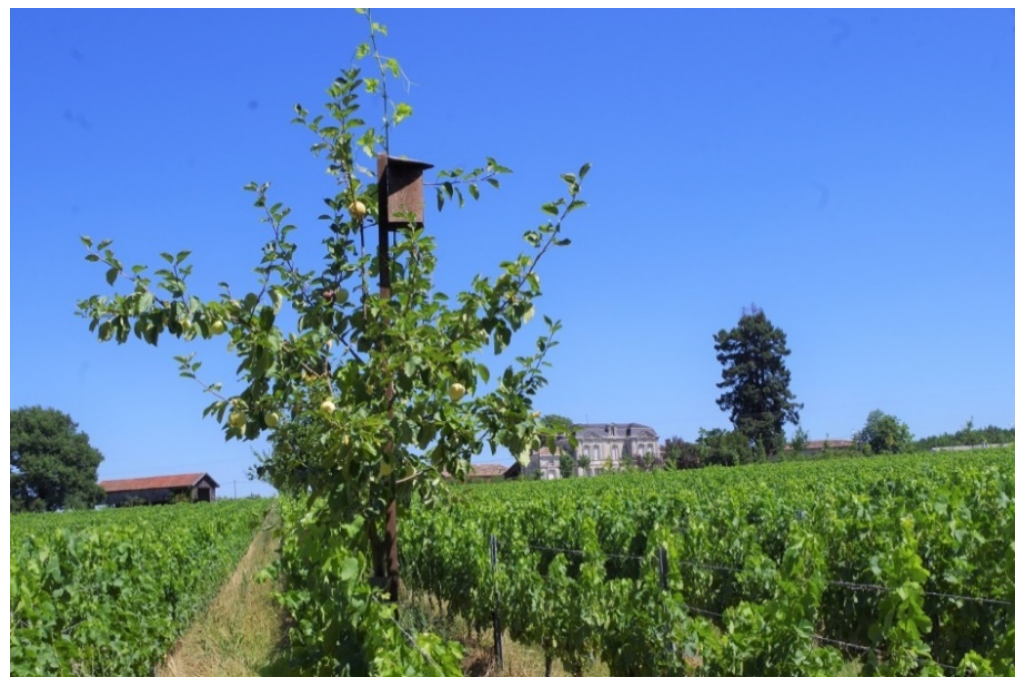

Figure 11. An agroecological vineyard studied: Domaine Emile Grelier.

agroecological practices are integrated are more complex, and they require more labour, frequent vineyard observations and adequate equipment for mechanical weeding and applying phytosanitary treatments. Performing such operations in a large vineyard can be more difficult if there is not enough qualified labour.

Viticultural systems that were classified by the MCDA method in the high-performance category have a field size ranging from 8 to 40 ha. This constraint could make it more difficult for some conventional winegrowers with large vineyards ( $>40 \mathrm{ha}$ ) to develop more agroecological practices.

In the study area, the vineyard "Domaine Emile Grelier" (VS59) is a good example of a successful viticultural system in which a holistic agroecological approach is applied, and which was assigned by the MCDA to the "very high performance" category (Figure 11).

This VS has an area that did not exceed 10 ha. According to the vineyard manager the optimal area for one winegrower in an agroecological system should be around 10 - 15 ha for it to be really efficient. A varied landscape (e.g., natural wooded areas, hedges and ponds) is beneficial for making the transition to an agroecological system; it is therefore important to maintain these natural features or to develop them. Adopting an agroecological approach in viticulture could benefit product promotion (high selling price), since consumers are becoming increasingly aware of environmental and human health issues. Furthermore, opening the vineyard to visitors to explain and promote the environmental and human health benefits of cultivation methods based on agroecological practices could help foster societal integration in viticulture.

\section{Conclusions}

In order to shift to more sustainable agriculture with less impact on the environment and human health, it is important to design and assess new systems which integrate the principles of agroecology. 
In our study, we used MCDA and ELECTRE Tri-C \& III methods to evaluate existing viticultural systems. We identified viticultural practices that reconcile economic performance with environmental performance. Then we built scenarios in which practices were altered for each cultivation method (conventional and organic) to prove that these systems can be economically viable and significantly reduce the use of pesticides and their theoretical ecotoxicity.

Our models therefore showed that it is possible to optimise each method of cultivation by 1 ) adopting the right combination of viticultural practices, 2) taking into account the economic and technical constraints, and 3) choosing the adequate molecules and treatments to be used, as well as the appropriate equipment.

The proposed scenarios are based on existing practices and could be successfully adopted by winegrowers in different viticultural areas. However, in order to do so, regular expert advice and monitoring would be necessary to guide vineyards in their transition towards agroecological methods. Furthermore, winegrowers would need to carry out regular observations in the vineyard in order to assess, for example, pest pressure and biological regulation.

In conclusion, the holistic agroecological approach appears to be the best solution for facing the multiple societal challenges of agriculture and particularly viticulture.

\section{Acknowledgements}

We warmly acknowledge all the partners in this study: the winery of Tutiac, the wine trade union of the independent winegrowers, all the winegrowers, Delphine \& Benoit Vinet of the Domaine Emile Grelier for imparting their experience in agroecology, the Interprofessional Council of Bordeaux Wines (CIVB), the Gironde Chamber of Agriculture, the French Institute for Vine and Wine (IFV), the local authorities along the Gironde estuary, and the Val-de-Livenne local authority.

We would like to thank Adeline Ugaglia (Bordeaux Sciences Agro) for her valuable and helpful comments, and Kevin Petit (INRAE) for his help in the field surveys. We are also grateful to Stephanie Hayes (Hayes4Com) for copyediting the text.

\section{Funding}

This work was carried out as part of the PhytoCOTE project, with financial support from the ANR within the framework of the Investments for the Future Program, the Laboratory of Excellence COTE (ANR-10-labex-45), and the New Aquitaine Regional Council (2015-1R20602).

\section{Conflicts of Interest}

The authors declare no conflicts of interest regarding the publication of this paper. 


\section{References}

[1] Barriuso, E. (2004) Estimation des risques environnementaux des 687 pesticides. INRA éditions, Paris, $113 \mathrm{p}$.

[2] Nicholls, C. and Altieri, M. (2014) Agroecology: Designing Climate Change Resilient Small Farming Systems in the Developing World. Agroecology for Food Security and Nutrition, Proceedings of the FAO International Symposium, Rome, 271-295.

[3] Van der Werf, H.M.G. (1996) Assessing the Impact of Pesticides on the Environment. Agriculture, Ecosystems \& Environment, 60, 81-96. https://doi.org/10.1016/S0167-8809(96)01096-1

[4] Alavanja, M.R., Hoppin, J.A. and Kamel, F. (2004) Health Effects of Chronic Pesticide Exposure: Cancer and Neurotoxicity. Annual Review of Public Health, 25, 155-197. https://doi.org/10.1146/annurev.publhealth.25.101802.123020

[5] Baldi, I., Lebailly, P., Rondeau, V., et al. (2012) Levels and Determinants of Pesticide Exposure in Operators Involved in Treatment of Vineyards: Results of the PESTEXPO Study. Journal of Exposure Science and Environmental Epidemiology, 22, 593-600. https://doi.org/10.1038/jes.2012.82

[6] Bohnen, N.I. and Kurland, L.T. (1995) Brain Tumor and Exposure to Pesticides in Humans: A Review of the Epidemiologic Data. Journal of the Neurological Sciences, 132, 110-121. https://doi.org/10.1016/0022-510X(95)00151-Q

[7] Costello, S., Cockburn, M., Bronstein, J., Zhang, X. and Ritz, B. (2009) Parkinson's Disease and Residential Exposure to Maneb and Paraquat from Agricultural Applications in the Central Valley of California. The American Journal of Epidemiology, 169, 919-926. https://doi.org/10.1093/aje/kwp006

[8] Bengtsson, J., Enstrom, J. and Weibull, A.C. (2005) The Effects of Organic Agriculture on Biodiversity and Abundance: A Meta-Analysis. Journal of Applied Ecology, 42, 261-269. https://doi.org/10.1111/j.1365-2664.2005.01005.x

[9] Kremen, C., Williams, N.M. and Thorp, R.B. (2002) Crop Pollination from Native Bees at Risk from Agricultural Intensification. PNAS, 26, 16812-16816.

http://www.pnas.org/content/99/26/16812.full

https://doi.org/10.1073/pnas.262413599

[10] Berendse, F., Chamberlain, D., Kleijn, D. and Schekkerman, H. (2004) Declining Biodiversity in Agricultural Landscapes and the Effectiveness of Agri-Environments Chemes. AMBIO: A Journal of the Human Environment, 33, 499-502. https://doi.org/10.1579/0044-7447-33.8.499

[11] Wezel, A., Bellon, S., Doré, T., Francis, C., Vallod, D. and David, C. (2009) Agroecology as a Science, a Movement and a Practice. A Review. Agronomy for Sustainable Development, 29, 503-515. https://doi.org/10.1051/agro/2009004

[12] FAO (2018) The 10 Elements of Agroecology. Guiding the Transition to Sustainable Food and Agricultural Systems. Food and Agriculture Organization of the United Nations, Rome.

[13] Macary, F., Guerendel, F. and Alonso Ugaglia, A. (2020) Quels apports de la littérature pour comprendre et construire la transition agroécologique en viticulture? Cahiers Agriculture, 29, 38. https://doi.org/10.1051/cagri/2020035

[14] Altieri, M.A. (1995) Agroecology: The Science of Sustainable Agriculture. Westeview Press, Boulder, 433 p.

[15] Baret, P. (2017) Un changement de paradigme. Messages du Secours Catholi- 
que-Caritas France 720, 16.

[16] Gary, C., Metral, R., Metay, A., Garcia, L., Merot, A., Smits, N., et al. (2017) Towards an Agroecological Viticulture: Advances and Challenges. Proceedings of the 20 th GIESCO International Meeting, Mendoza, 5-10 November 2017, 1122-1127. https://hal.archivesouvertes.fr/hal-01664474

[17] Garcia, L., Damour, G., Gary, C., Follain, S., Le Bissonnais, Y. and Metay, A. (2019) Trait-Based Approach for Agroecology: Contribution of Service Crop Root Traits to Explain Soil Aggregate Stability in Vineyards. Plant and Soil, 435, 1-14. https://doi.org/10.1007/s11104-018-3874-4

[18] Nicholls, C., Altieri, M., Dezanet, A., Lana, M., Feistauer, D. and Ouriques, M. (2004) A Rapid, Farmer-Friendly Agroecological Method to Estimate Soil Quality and Crop Health in Vineyard Systems. Biodynamics, 33, 822-840.

http://agroecology.pbworks.com/f/biodyn-indicators.pdf

[19] Vereijken, P. (1997) A Methodical Way of Prototyping Integrated and Ecological Arable Farming Systems (I/EAFS) in Interaction with Pilot Farms. Developments in Crop Science, 25, 293-308. https://doi.org/10.1016/S0378-519X(97)80029-3

[20] Lançon, J., Wery, J., Rapidel, B., Angokaye, M., Gérardeaux, E., Gaborel, C., Ballo, D. and Fadegnon, B. (2007) An Improved Methodology for Integrated Crop Management Systems. Agronomy for Sustainable Development, 27, 101-110. https://doi.org/10.1051/agro:2006037

[21] Metral, R., Rapidel, R., Delière, L., Petitgenet, M., Lafond D., Chevrier, C., Bernard, F.M., Serrano, E., Thiolet-Scholtus, M. and Wery, J. (2015) A Prototyping Method for the Re-Design of Intensive Perennial Systems: The Case of Vineyards in France. 5th International Symposium for Farming Systems Design, Montpellier, 7-10 September 2015, 2 p.

[22] Debaeke, P., Munier-Jolain, N.M., Bertrand, M., Guichard, L., Nolot, J.M., Faloya, V. and Saulas, P. (2009) Iterative Design and Evaluation of Rule-Based Cropping Systems: Methodology and Case Studies. A Review. Agronomy for Sustainable Development, 29, 73-86. https://doi.org/10.1051/agro:2008050

[23] Bergez, J.E., Colbach, N., Crespo, O., Garcia, F., Jeuffroy, M.H., Justes, E., Loyce, C., Munier-Jolain, N. and Sadok, W. (2010) Designing Crop Management Systems by Simulation. European Journal of Agronomy, 32, 3-9.

https://doi.org/10.1016/j.eja.2009.06.001

[24] Sadok, W., Angevin, F., Bergez, J.E., Bockstaller, C., Colomb, B., Guichard, L., Reau, R. and Dore, T. (2009) MASC, a Qualitative Multi-Attribute Decision Model for Ex Ante Assessment of the Sustainability of Cropping Systems. Agronomy for Sustainable Development, 29, 447-461. https://doi.org/10.1051/agro/2009006

[25] Pelzer, E., Fortino, G., Bockstaller, C., Angevin, F., Lamine, C., Moonen, C., Vasileiadis, V., Guérin, D., Guichard, L., Reau, R. and Messéan, A. (2012) Assessing Innovative Cropping Systems with DEXiPM, a Qualitative Multi-Criteria Assessment Tool Derived from DEXi. Ecological Indicators, 18, 171-182. https://doi.org/10.1016/j.ecolind.2011.11.019

[26] Deytieux, V., Munier-Jolain, N.M. and Caneill, J. (2015) Assessing the Sustainability of Cropping Systems in Single- and Multi-Sites Studies. A Review of Methods. $E u-$ ropean Journal of Agronomy, 72, 107-126. https://doi.org/10.1016/j.eja.2015.10.005

[27] Arondel, C. and Girardin, P. (2000) Sorting Cropping Systems on the Basis of Their Impact on Groundwater Quality. European Journal of Operational Research, 3, 467-482. https://doi.org/10.1016/S0377-2217(99)00437-3 
[28] Loyce, C., Rellier, J.P. and Meynard, J.M. (2002) Management Planning for Winter Wheat with Multiple Objectives (1): The BETHA System. Agricultural Systems, 72, 9-31. https://doi.org/10.1016/S0308-521X(01)00064-6

[29] Macary, F., Almeida-Dias, J., Uny, D. and Probst, A. (2013) Assessment of the Effects of Best Environmental Practices on Reducing Pesticide Pollution in Surface Water, Using Multi-Criteria Modelling Combined with a GIS. International Journal of Multi-Criteria Decision Making, 3, 178-211. https://doi.org/10.1504/IJMCDM.2013.053725

[30] Macary, F., Almeida Dias, J., Rui-Figueira, J. and Roy, B. (2014) A Multiple Criteria Decision Analysis Model Based on ELECTRE TRI-C for Erosion Risk Assessment in Agricultural Areas. Environmental Modeling \& Assessment, 19, 221-242. https://doi.org/10.1007/s10666-013-9387-x

[31] Roy, B. (1968) Classement et choix en présence de points de vue multiples (la méthode ELECTRE). Revue française d'automatique, dinformatique et de recherche opérationnelle, 8, 57-75. https://doi.org/10.1051/ro/196802V100571 http://www.numdam.org/item?id=RO $\begin{array}{lllll}1968 & 2 & 1 & 57 & 0\end{array}$

[32] Roy, B. (1985) Méthodologie multicritère d'aide à la décision. Multicriteria methodology for decision aiding, Economica, Paris, $424 \mathrm{p}$.

[33] Almeida-Dias, J., Rui-Figueira, J. and Roy, B. (2006) The Software ELECTRE III-IV, Methodology and User Manual (Version 3x), Cahiers du LAMSADE, Université Paris-Dauphine.

[34] Almeida-Dias, J., Rui-Figueira, J. and Roy, B. (2010) ELECTRE TRI-C: A Multiple Criteria Sorting Method Based on Characteristic Reference Actions. European Journal of Operational Research, 204, 565-580.

https://doi.org/10.1016/j.ejor.2009.10.018

[35] Roy, B. (1990) The Outranking Approach and the Foundations of ELECTRE Methods. In: Readings in Multiple Criteria Decision Aid, Springer-Verlag, Heidelberg, 155-183. https://doi.org/10.1007/978-3-642-75935-2 8

[36] Mghirbi, O., Ellefi, K, Le Grusse, P., Mandart, E., Fabre, J., Ayadi, H. and Bord, J. P. (2016) Assessing Plant Protection Practices Using Pressure Indicator and Toxicity Risk Indicators: Analysis of the Relationship between These Indicators for Improved Risk Management, Application in Viticulture. Environmental Science and Pollution Research, 22, 8058-8074. https://doi.org/10.1007/s11356-014-3736-4

[37] Figueira, J. and Roy, B. (2002) Determining the Weights of Criteria in the ELECTRE Type Methods with a Revised Simos' Procedure. European Journal of Operational Research, 139, 317-326. https://doi.org/10.1016/S0377-2217(01)00370-8

[38] El Hadri, H., Chéry, P., Jalabert, S., Lee, A., Potin-Gautier, M. and Lespes, G. (2012) Assessment of Diffuse Contamination of Agricultural Soil by Copper in Aquitaine Region by Using French National Databases. Science of the Total Environment, 441, 239-247. https://doi.org/10.1016/j.scitotenv.2012.09.070

[39] Toselli, M., Schiatti, P., Ara, D., Bertacchini, A. and Quartieri, M. (2009) The Accumulation of Copper in Soils of the Italian Region Emilia-Romagna. Plant Soil Environment, 50, 74-79. https://doi.org/10.17221/317-PSE

[40] Delmotte, S., Ripoche, A. and Gary, C. (2008) A Multiple Criteria Assessment Approach for Evaluating the Sustainability of Innovative Cropping Systems in Viticulture. ENDURE International Conference, La Grande-Motte, 4 p.

[41] Lafon, D., Coulon, T., Metral, R., Mérot, A. and Wéry, J. (2013) EcoViti: A Systemic Approach to Design Low Pesticide Vineyards. Integrated Protection and Production 
in Viticulture. IOBC-WPRS Bulletin, 85, 77-86.

[42] Metral, R., Chevrier, C., Bals, N., Bouisson, Y., Didier, V., Enard, C., Fremond, N., Garin, P., Gautier, T., Genevet, B., Goma-Fortin, N., Guillois, F., Ohl, B. and Thiery, J. (2018) DEPHY EXPE EcoViti French Mediterranean Belt Project: Synthesis of 2012-2017 Results. Innovations Agronomiques, 70, 3-20.

[43] Doody, D.G., Kearney, P., Barry, J., Moles, R. and O’Regan, B. (2009) Evaluation of the q-Method as a Method of Public Participation in the Selection of Sustainable Development Indicators. Ecological Indicators, 9, 1129-1137.

https://doi.org/10.1016/j.ecolind.2008.12.011

[44] Santiago-Brown, I., Metcalfe, A., Jerram, C. and Collins, C. (2015) Sustainability Assessment in Wine-Grape Growing in the New World: Economic, Environmental, and Social Indicators for Agricultural Businesses. Sustainability, 7, 8178-8204. https://doi.org/10.3390/su7078178

[45] Wezel, A., Casagrande, M., Celette, F., Vian, J.-F., Ferrer, A. and Peigné, J. (2014) Agroecological Practices for Sustainable Agriculture. A Review. Agronomy for Sustainable Development, 34, 1-20. https://doi.org/10.1007/s13593-013-0180-7 https://hal.archives-ouvertes.fr/hal-01234800/document

[46] Merot, A. and Wéry, J. (2017) Converting to Organic Viticulture Increases Cropping System Structure and Management Complexity. Agronomy for Sustainable Development, 37, Article No. 19. https://doi.org/10.1007/s13593-017-0427-9 


\section{Appendices}

Appendix 1. Description of the Practices Adopted for Each Total Revenue Reference (in CR1: REN)

\begin{tabular}{|c|c|c|c|c|c|c|}
\hline \multirow{3}{*}{ References } & Ref 1 & $\operatorname{Ref} 2$ & Ref 3 & $\operatorname{Ref} 4$ & Ref 5 & Ref 6 \\
\hline & \multicolumn{6}{|c|}{ Conventional wines } \\
\hline & $\begin{array}{c}\text { Organic } \\
\text { wine }\end{array}$ & $\begin{array}{l}\text { Red wine } \\
\text { Ruby }\end{array}$ & $\begin{array}{l}\text { Red wine } \\
\text { Garnet }\end{array}$ & $\begin{array}{l}\text { Red wine } \\
\text { Ocher }\end{array}$ & $\begin{array}{l}\text { Red wine } \\
\text { Brick }\end{array}$ & $\begin{array}{l}\text { White } \\
\text { wine }\end{array}$ \\
\hline $\begin{array}{l}\text { Full disbudding or unwanted shoots } \\
\text { removal }\end{array}$ & $\mathrm{x}$ & $\mathrm{x}$ & $\mathrm{x}$ & $\mathrm{x}$ & $\mathrm{x}$ & \\
\hline Good distribution of grapes & $\mathrm{x}$ & $\mathrm{x}$ & $\mathrm{x}$ & $\mathrm{x}$ & & \\
\hline Good vigour & $\mathrm{x}$ & $\mathrm{x}$ & & & & \\
\hline $\begin{array}{l}\text { At least one treatment against } \\
\text { Botrytis per year }\end{array}$ & & & $\mathrm{x}$ & & & \\
\hline Grass cover on one row or soil tillage & (x) & & & & $\mathrm{x}$ & $\mathrm{x}$ \\
\hline Grass cover at all the rows & $(\mathrm{x})$ & $(\mathrm{x})$ & $(\mathrm{x})$ & $(\mathrm{x})$ & & \\
\hline Lump sum total revenue: $€ /$ ha & 8000 & 7800 & 6300 & 5700 & 5400 & 7000 \\
\hline
\end{tabular}

(X) adaptable practice according to the year

Appendix 2. Reference on the Ration Toxicity/Exposition Defined by the Product Registration Directive

\begin{tabular}{ccc}
\hline Animal species & Acrute toxicity/short term & Chronic toxicity \\
\hline Birds and other vertebrate & DL50 $0^{30} /$ exposition $>10$ & CSEO $^{31} /$ exposition $>5$ \\
Fish and daphnia & DL50 $0^{32} /$ exposition $>100$ & CSEO/exposition $>10$ \\
Earthworms & DL50/exposition $>10$ & DL50 $50 /$ exposition $>10$ \\
Bee & DHm.a ${ }^{33} /$ DL50 $<50$ & - \\
\hline
\end{tabular}

Source: Directive 91/414/CCE

Appendix 3. Classification of the Spray Equipment Regarding Drift Control and Notation

\begin{tabular}{ccc}
\hline Spray quality for drift limitation & Spraying devices & Note \\
\hline Very high & Confined sprayer (mostly) & 8 \\
High & face to face spraying & 6 \\
Medium & Air blower (mostly/other better equipment) & 4 \\
Low & Air blower & 2 \\
Very low & air blast sprayer & 1 \\
\hline
\end{tabular}


Appendix 4. Assessment of the Complexity of the Implementation of the Wine System and Notation of Performances Using Electre TRI-C Model

\begin{tabular}{ccc}
\hline Number of operations & Distance & Note \\
\hline \multirow{2}{*}[20-25]{} & Around the farm & 1 \\
& $\mathrm{~d}<5 \mathrm{~km}$ & 4 \\
$\mathrm{~d}>5 \mathrm{~km}$ & 7 \\
\hline $325-30]$ & Around the farm & 9 \\
& $\mathrm{~d}<5 \mathrm{~km}$ & 12 \\
\hline $30-35]$ & $\mathrm{d}>5 \mathrm{~km}$ & 15 \\
\hline & Around the farm & 17 \\
& $\mathrm{~d}<5 \mathrm{~km}$ & 20 \\
& $\mathrm{~d}>5 \mathrm{~km}$ & 23 \\
\hline $35-40]$ & Around the farm & 25 \\
& $\mathrm{~d}<5 \mathrm{~km}$ & 28 \\
& $\mathrm{~d}>5 \mathrm{~km}$ & 31 \\
\hline & Around the farm & 33 \\
& $\mathrm{~d}<5 \mathrm{~km}$ & 36 \\
& $\mathrm{~d}>5 \mathrm{~km}$ & 39 \\
\hline
\end{tabular}

Appendix 5. Matrix of Viticultural Systems Performance

\begin{tabular}{cccccccc}
\hline Alternatives & REN & PPS & IRE & PAE & PUL & TRA & SYS \\
\hline SV04 & 2196 & 16 & 4553 & 3 & 1 & 243 & 23 \\
SV05 & 2048 & 16 & 3424 & 1 & 6 & 294 & 31 \\
SV07 & 2013 & 13 & 3151 & 1 & 8 & 272 & 31 \\
SV08 & 2329 & 17 & 4690 & 1 & 8 & 251 & 20 \\
SV09 & 3180 & 9 & 6980 & 46 & 1 & 320 & 20 \\
SV10 & 2157 & 16 & 4072 & 1 & 1 & 256 & 15 \\
SV11 & 1694 & 15 & 4235 & 3 & 1 & 263 & 23 \\
SV18 & 2128 & 16 & 5437 & 1 & 1 & 237 & 15 \\
SV22 & 1768 & 18 & 3859 & 1 & 1 & 234 & 23 \\
SV23 & 1744 & 17 & 4355 & 33 & 1 & 274 & 28 \\
SV31 & 2907 & 18 & 5413 & 21 & 1 & 257 & 12 \\
SV32 & 2275 & 16 & 4412 & 1 & 1 & 235 & 9 \\
SV33 & 2053 & 12 & 7512 & 21 & $\mathbf{8}$ & 271 & 23 \\
SV34 & 1873 & 17 & 6863 & 3 & 8 & 273 & 20 \\
SV36 & 2075 & 15 & 4613 & 31 & 4 & 220 & 15 \\
SV38 & 3509 & 7 & 9218 & 26 & 1 & 284 & 17 \\
SV39 & 3592 & 10 & 9754 & 46 & 1 & 262 & 31 \\
SV40 & 3448 & 9 & 9504 & 46 & 1 & 283 & 31 \\
\hline
\end{tabular}


Continued

\begin{tabular}{|c|c|c|c|c|c|c|c|}
\hline SV42 & 3118 & 8 & 6571 & 46 & 1 & 310 & 20 \\
\hline SV50 & 2354 & 16 & 4788 & 33 & 1 & 248 & 20 \\
\hline SV51 & 1905 & 20 & 4895 & 35 & 2 & 249 & 17 \\
\hline SV52 & 1693 & 16 & 4983 & 41 & 1 & 257 & 20 \\
\hline SV53 & 1510 & 17 & 3398 & 31 & 3 & 241 & 12 \\
\hline SV54 & 2697 & 7 & 7265 & 16 & 1 & 327 & 23 \\
\hline SV55 & 3368 & 11 & 8490 & 26 & 6 & 296 & 23 \\
\hline SV56 & 2958 & 17 & 3224 & 1 & 6 & 226 & 17 \\
\hline SV57 & 1284 & 16 & 5083 & 35 & 2 & 250 & 20 \\
\hline SV58 & 2051 & 18 & 3213 & 41 & 4 & 231 & 15 \\
\hline SV59 & 3917 & 11 & 10,383 & 56 & 1 & 261 & 9 \\
\hline SV60 & 1555 & 16 & 3296 & 31 & 8 & 321 & 39 \\
\hline SV61 & 2510 & 18 & 3178 & 11 & 2 & 229 & 15 \\
\hline SV62 & 2669 & 14 & 4496 & 45 & 2 & 241 & 15 \\
\hline SV63 & 2230 & 15 & 3210 & 5 & 2 & 235 & 12 \\
\hline SV64 & 1976 & 20 & 5817 & 11 & 2 & 256 & 9 \\
\hline SV65 & 1731 & 18 & 4231 & 35 & 1 & 220 & 7 \\
\hline SV66 & 2212 & 15 & 8738 & 51 & 4 & 304 & 25 \\
\hline SV67 & 3164 & 13 & 4286 & 6 & 2 & 218 & 20 \\
\hline SV68 & 1207 & 14 & 4076 & 6 & 1 & 238 & 12 \\
\hline SC_1 & 3062 & 11 & 4886 & 46 & 8 & 292 & 12 \\
\hline SC_2 & 3617 & 10 & 4950 & 56 & 8 & 232 & 4 \\
\hline SC_3 & 4274 & 7 & 7283 & 56 & 8 & 268 & 12 \\
\hline
\end{tabular}

Organic systems/Systems with environmental certification/Conventional systems.

Appendix 6. Method of SRF (Simos, Roy, Figueira) for Weighting Criteria of Evaluation

(1) Associating a 'playing card' to each criterion

\begin{tabular}{|l|l|l|l|l|l|l|l|l|l|l|l|l|}
\hline TRA & PAE & REN & PPS & SYS & IRE & PUL \\
\hline
\end{tabular}

(2) Ranking the criteria from the most important one to the less important

\begin{tabular}{|l|l|l|l|l|l|l|}
\hline REN & PPS & IRE & PAE & PUL & TRA & SYS \\
\hline
\end{tabular}

(3) Inserting white cards $(\triangle)$ : Degree of importance of the criterion regarding to the following one

\begin{tabular}{|c|c|c|c|c|c|c|c|}
\hline $\begin{array}{l}\text { CR } 1 . \\
\text { REN }\end{array}$ & $\begin{array}{l}\text { CR } 2 . \\
\text { PPS }\end{array}$ & $\Delta$ & $\begin{array}{c}\text { CR } 3 . \\
\text { IRE }\end{array}$ & $\begin{array}{l}\text { CR } 4 . \\
\text { PAE }\end{array}$ & $\begin{array}{l}\text { CR } 5 . \\
\text { PUL }\end{array}$ & $\begin{array}{c}\text { CR } 6 . \\
\text { TRA }\end{array}$ & $\begin{array}{l}\text { CR } 7 . \\
\text { SYS }\end{array}$ \\
\hline
\end{tabular}

(4) Determining the number of times the most important criterion dominates the less important one : $\mathrm{Z}=3 \rightarrow \mathrm{CR} 1 / \mathrm{CR} 7=3$ 
Appendix 7. Preference Threshold $\left(p_{g}\right)$ and Indifference Threshold $\left(q_{g}\right)$ Assigned to Each Criterion

\begin{tabular}{cccccccc}
\hline & REN & PPS & IRE & PAE & PUL & TRA & SYS \\
\hline Weights & 22 & 20 & 15 & 13 & 13 & 10 & 7 \\
Threshold indifference & 0.05 & 0.03 & 0.05 & 1 & 1.9 & 0.025 & 1 \\
Threshold preference & 0.1 & 0.07 & 0.1 & 1.9 & 1.9 & 0.05 & 2.9 \\
Criterion direction & MAX & MIN & MIN & MAX & MAX & MIN & MIN \\
\hline
\end{tabular}

Appendix 8. Results of Sorting the Existing Viticultural Systems in the Four Categories

\begin{tabular}{cccc}
\hline Categories & Performances & Viticultural systems & Number \\
\hline C1 & Very high performance & VS 59 & $3(7.3 \%)$ \\
\hline \multirow{2}{*}{ C2 } & High performance & $\begin{array}{c}\text { SC1, SV07, VS09, VS38, VS39, VS40, VS42, } \\
\text { VS54, VS55, VS56, VS61, VS62, VS67 }\end{array}$ & $13(31.7 \%)$ \\
& & VS04, VS05, VS08, VS10, VS11, VS18, VS23, & \\
& VS31, VS32, SV33, VS36, VS50, SV51, SV52, & $23(56 \%)$ \\
C3 & Medium performance & SV53, SV57, VS58, VS60, VS63, VS64, VS65, & VS66, VS68 \\
& & VS22, VS34 & $2(5 \%)$ \\
\hline C4 & Low performance & V
\end{tabular}

Organic systems/Systems with environmental certification/Conventional system. 